\title{
Características Químicas da Digesta de Bezerros Provenientes de Rebanhos Leiteiros Alimentados com Dietas Contendo Diferentes Níveis de Concentrado ${ }^{1}$
}

\section{José Carlos Pereira², Samuel Pereira de Freitas ${ }^{3}$, Augusto César de Queiroz ${ }^{2}$, José Fernando Coelho da Silva ${ }^{2}$, Sebastião de Campos Valadares Filho², Gherman Garcia Leal de Araújo ${ }^{4}$}

RESUMO - Este trabalho foi conduzido para se avaliar o efeito de diferentes níveis de concentrado na dieta sobre os teores de matéria seca (MS), fibra em detergente neutro (FDN), fibra em detergente ácido (FDA) e proteína bruta (PB) da digesta, em diferentes seções do trato gastrintestinal (TGI) de bezerros provenientes de rebanhos leiteiros. Trinta e dois bezerros machos não-castrados, metade Holandeses puros por cruza e metade mestiços Holandes-Zebu, foram abatidos, após jejum de 16 horas, com média de 6 meses idade e $190 \mathrm{~kg}$ PV final. As dietas, fornecidas à vontade, foram constituídas de feno de capim coast-cross e diferentes níveis de concentrado na ração (milho moído, farelo de soja, calcário e sal mineral), 45,0; 60,0; 75,0; e 90,0\%. Não houve diferenças entre os bezerros Holandeses e mestiços Holandes-Zebu neste estudo. Os teores de MS no retículo-rúmen e no intestino delgado não diferiram; houve efeito linear crescente, no intestino grosso e no omaso e abomaso, efeito quadrático, em relação aos níveis de concentrado na ração. Os teores de FDN e FDA mantiveram-se constantes no rúmen-retículo e nas demais seções do TGI, houve efeito linear crescente. No retículo-rúmen e no intestino grosso, os teores de PB mantiveram-se constantes; no omaso, abomaso e intestino delgado, houve efeito linear crescente e, no intestino delgado, foram encontrados os maiores teores de PB.

Palavras-chave: bezerro, nível de concentrado, nutriente, trato gastrintestinal

\section{Chemical Characteristics of Dairy Calves Digesta Fed Diets with Different Levels of Concentrate}

\begin{abstract}
This research was carried out to evaluate the effect of different levels of concentrate in the diet on the contents of dry matter (DM), neutral detergent fiber (NDF), acid detergent fiber (ADF) and crude protein (CP) of the digesta, in the distinct sections of the gastrointestinal tract (GIT) of the dairy calves. Thirty-two young bulls were used, half Holstein and the other half crossbred HolsteinZebu, were slaughtered with an average age of six months and $190 \mathrm{~kg} \mathrm{LW}$ final after fasting of $16 \mathrm{~h}$. The diets, ad libitum fed, were constituted of coast-cross hay and different dietary concentrate levels (ground corn, soybean meal, limestone and mineral salt), levels: 45.0, 60.0, 75.0 and $90.0 \%$. There were no differences between Holstein calves and crossbred Holstein-Zebu in this study. The DM content in the reticulumrumen and small intestine did not differ; in the large intestine there was a crescent linear effect, and in the omasum and abomasum, a quadratic effect on the concentrate levels in the diet. The NDF and ADF contents maintained constant in the reticulum-rumen, and in the other sections of GIT there was a crescent linear effect. In the reticulum-rumen and large intestine, the CP contents maintained constant; in the omasum, abomasum and small intestine there was a crescent linear effect, and the highest CP contents were found in the small intestine.
\end{abstract}

Key Words: dairy calf, concentrate level, nutrient, gastrointestinal tract

\section{Introdução}

Um aspecto básico em nutrição de ruminantes consiste em fornecer a alimentação volumosa e concentrada em proporções adequadas, de modo a obter resposta máxima pelo animal. Entretanto, em sistemas de produção intensiva de bezerros provenientes de rebanhos leiteiros, as informações são escassas ou nulas, devido à ausência deste tipo de atividade em nosso meio criatório.

$\mathrm{O}$ valor nutritivo das dietas dos ruminantes é influenciado pela taxa em que os nutrientes são degradados no rúmen e pela taxa de remoção das partículas que influi na saída de material do rúmenretículo e na concentração dos nutrientes por meio do trato gastrintestinal (OSBOURN et al., 1976; POPPI et al., 1980). A quantidade de fibra em detergente neutro (FDN) da dieta e a eficiência da ruminação dos animais são importantes para determinar o tempo necessário para trituração eficiente e favorecer $o$ escape do rúmen-retículo.

\footnotetext{
${ }^{1}$ Parte da tese de Mestrado do segundo autor - DZO - UFV

${ }^{2}$ Professor Titular do DZO-UFV, Bolsista do CNPq.

${ }^{3}$ Técnico da EMATER-MG.

${ }^{4}$ Pesquisador da EMBRAPA-Petrolina-PE.
} 
O rúmen-retículo está ocupado por uma massa supostamente homogênea, que pode representar até $20 \%$ do peso vivo do animal (CZERKAWSKY, 1986) e abrigar até $75 \%$ do total de matéria seca presente no trato digestivo, e por uma densa rede de partículas banhadas pelo líquido ruminal (CZERKAWSKY, 1986; VAN SOEST, 1994).

O teor de matéria seca do conteúdo total do omaso é aproximadamente de 19 a 29,5\%, enquanto o efluxo possui teor de 5 a 7\% (SMITH, 1984).

A função do omaso não é bem conhecida, mas sabe-se que água, amônia, ácidos graxos voláteis e eletrólitos inorgânicos, como sódio e potássio, são absorvidos nesse compartimento, e que talvez a amônia e alguns ácidos graxos voláteis são produzidos (UMPHREY e STAPLES, 1994).

A mucosa do abomaso secreta enzimas (pepsina) e ácido clorídrico que abaixam rapidamente o $\mathrm{pH}$ da digesta, em torno de 6,0 para 2,5 aproximadamente, criando condições para a quebra das proteínas em unidades menores: peptídeos e aminoácidos (UMPHREY e STAPLES, 1994).

A digesta, quando entra no intestino delgado, é misturada com secreções do fígado e pâncreas, as quais elevam o $\mathrm{pH}$ de 2,5 para aproximadamente 7,0 a 8,0. Este aumento de $\mathrm{pH}$ é necessário para que as enzimas se tornem ativas e ocorra redução do restante de proteína a aminoácidos, amido à glicose e complexos de gorduras em ácidos graxos (UMPHREY e STAPLES, 1994).

A digesta no ceco e cólon proximal é submetida a contrações peristálticas e antiperistálticas, fazendo com que seja misturada, bem como movida em direção ao cólon distal. Ocorre produção e absorção de ácidos graxos voláteis no intestino grosso, mas sua principal função é provavelmente a absorção de água (FORBES e FRANCE, 1993). Portanto, os objetivos deste trabalho foram determinar os efeitos de diferentes níveis de concentrado na dieta sobre as características químicas da digesta em diferentes seções do trato gastrintestinal (TGI) de bezerros provenientes de rebanhos leiteiros.

\section{Material e Métodos}

\section{Animais e dietas}

Foram utilizados neste estudo 32 bezerros em crescimento, sendo 16 Holandeses PC e 16 mestiços (Holandês X Zebu), todos não-castrados, com idade aproximada de 60 dias e peso vivo médio inicial de 60 $\mathrm{kg}$. Os bezerros Holandeses foram criados do nasci- mento até o início do experimento em um único sistema de aleitamento, no qual receberam quatro litros de leite, fornecidos duas vezes ao dia, durante 60 dias. Neste período, sempre tiveram à disposição, nos comedouros, feno de capim coast-cross (Cynodon dactilon) moído e ração concentrada. Os bezerros mestiços, a partir do nascimento aos 60 dias de idade, foram submetidos ao manejo que consistiu em separação das mães 24 horas após o nascimento; fornecimento de quatro litros de colostro em baldes duas vezes ao dia, do $2^{\circ}$ ao $4^{\circ}$ dia; fornecimento de quatro litros de leite, duas vezes ao dia, do $5^{\circ}$ ao $12^{\circ}$ dia; e fornecimento de um concentrado protéico com $16 \%$ PB e feno picado de grama batatais (Paspalum notatum, Flugge), pela manhã, e quatro litros de leite ao final da tarde, do $13^{\circ}$ ao $60^{\circ}$ dia. Após o desaleitamento, todos os bezerros tiveram um período de adaptação às dietas experimentais de 15 dias, e a partir dos 75 dias de idade, foram criados em regime de confinamento, em baias cobertas, com piso de concreto, providas de bebedouros e comedouros.

Foram formuladas quatro rações concentradas à base de farelo de soja, milho moído (fubá), calcário e sal mineralizado, cujas proporções dos ingredientes se encontram na Tabela 1. A composição químicobromatológica consta da Tabela 2 .

As rações experimentais foram calculadas com base nas exigências nutricionais recomendadas pelo NRC (1988), para ganho de peso médio de $700 \mathrm{~g} / \mathrm{dia}$, e preparadas com a utilização do feno de capim

Tabela 1 - Composição percentual dos ingredientes nas rações concentradas (\%MN)

Table 1 - Percentage composition of the ingredients in the concentrate diets (\% as fed)

\begin{tabular}{|c|c|c|c|c|}
\hline Ingrediente & \multicolumn{4}{|c|}{ Ração concentrada (Concentrate diet) } \\
\hline Ingredient & R45 & R60 & R75 & R90 \\
\hline Fubá de milho & 53,22 & 67,30 & 75,74 & 81,11 \\
\hline Corn meal & & & & \\
\hline Farelo de soja & 44,78 & 30,70 & 22,26 & 16,89 \\
\hline Calcário & 1,00 & 1,00 & 1,00 & 1,00 \\
\hline $\begin{array}{l}\text { Limestone } \\
\text { Sal mineral } \\
\text { Mineral salt }\end{array}$ & 1,00 & 1,00 & 1,00 & 1,00 \\
\hline $\begin{array}{l}\text { eralizac } \\
\text { de fosfa } \\
\text { e) } ; 519 \text {, }\end{array}$ & eraliseo & Cad & tém & $\begin{array}{l}\mathrm{kg} \text { con } \\
\text { e cal }\end{array}$ \\
\hline
\end{tabular}


coast-cross moído grosseiramente e de rações concentradas, nas proporções de concentrado:volumoso de 45:55; 60:40; 75:25; e 90:10\%, denominadas de tratamentos $\mathrm{C} 45, \mathrm{C} 60, \mathrm{C} 75$ e C90, respectivamente. $\mathrm{O}$ fornecimento foi feito na forma de dieta total. Todas as rações experimentais foram aproximadamente isoprotéicas, porém, variando o conteúdo energético (Tabela 2).

Abate dos animais, coleta e preparo das amostras

Os animais eram abatidos à medida que atingiam o peso médio de $190 \mathrm{~kg}$. Antes da última pesagem e abate, foram submetidos a jejum de 16 horas, porém com água à vontade. $\mathrm{O}$ abate foi feito por concussão cerebral e posterior secção da jugular. Para a evisceração, foi feita incisão a partir da mandíbula até o ânus, sendo o trato gastrintestinal (TGI) removido e pesado. Na seqüência, os compartimentos foram separados nas junções entre as seções rúmen-retículo e omaso, omaso e abomaso, abomaso e intestino delgado, intestino delgado e intestino grosso e, então, pesados cheio e vazio, após bem lavados e escorrida a água. Todo o conteúdo de cada seção foi homogeneizado em baldes separados e, então, amostrados. As amostras foram armazenados em congelador a $-15^{\circ} \mathrm{C}$, dentro de sacolas plásticas devidamente identificadas, para posteriores processamentos e análises.
Posteriormente, as amostras de digesta de cada seção do TGI foram descongeladas à temperatura ambiente, homogeneizadas e colocadas em recipientes de vidro para proceder à primeira pesagem, sendo em seguida levadas para a pré-secagem, conforme SILVA (1990). Após este período, os recipientes com amostras pré-secas foram novamente pesados, sendo o conteúdo moído em moinho tipo 'Willey", com peneira de 30 mesh, e após acondicionado em recipientes de vidro hermeticamente fechados.

As determinações de matéria seca definitiva (MS) e nitrogênio total foram realizadas segundo a metodologia descrita por SILVA (1990).

Para as determinações de fibra em detergente neutro (FDN), foi usado o procedimento descrito por VAN SOEST et al. (1991), com adição de amilase, e para análise de fibra em detergente ácido seqüencial (FDAs), a metodologia descrita por SILVA (1990).

O experimento foi montado em delineamento inteiramente casualizado, em um esquema de parcelas subdivididas, tendo nas parcelas o esquema fatorial $4 \times 2$, sendo quatro níveis de concentrado $(45,60,75$ e 90) e dois graus de sangue (HPC e mestiço), e nas subparcelas, as cinco seções do trato gastrintestinal (rúmen-retículo, omaso, abomaso, intestino delgado e intestino grosso), com quatro repetições, cujo modelo estatístico é expresso por:

Tabela 2 - Teor médio de nutrientes do feno, da ração concentrada e das dietas experimentais (\% MS)

Table 2 - Average nutrient content of the hay, concentrate diets and of the experimental diets (\% DM)

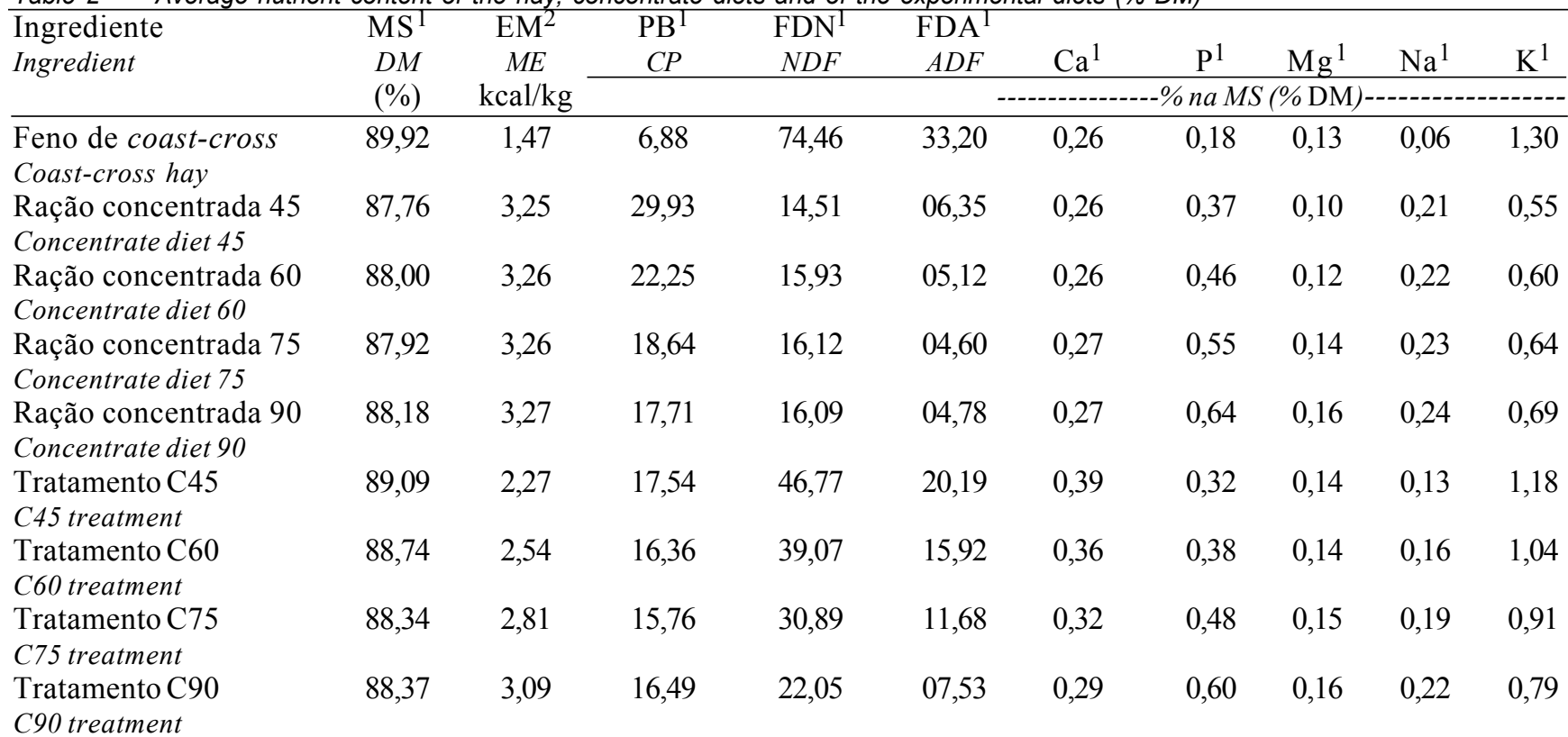

${ }^{1}$ Laboratório de Nutrição Animal do Departamento de Zootecnia da UFV (Animal Nutrition Laboratory of Federal University of Viçosa Animal Science Department)

2 NRC (1988). 
$\mathrm{Y}_{\mathrm{ijkl}}=\mu+\mathrm{A}_{\mathrm{i}}+\mathrm{B}_{\mathrm{j}}+\mathrm{AB}_{\mathrm{ij}}+\mathrm{E}_{(\mathrm{ij}) \mathrm{l}}+\mathrm{C}_{\mathrm{k}}+\mathrm{AC}_{\mathrm{ik}}$ $+\mathrm{BC}_{\mathrm{jk}}+\mathrm{ABC}_{\mathrm{ijk}}+\mathrm{E}_{\mathrm{ijkl}}$

em que

$\mathrm{Y}_{\mathrm{ijkl}}=$ observação referente ao animal 1, do nível de concentrado $i$, do grau de sangue j e da seção do trato gastrintestinal $\mathrm{k}$;

$\mu \quad=$ média geral;

$\mathrm{A}_{\mathrm{i}}=$ efeito do nível de concentrado $\mathrm{i}$, sendo $\mathrm{i}=1,2,3$ e 4 ;

$\mathrm{Bj} \quad=$ efeito do grau de sangue $\mathrm{j}$, sendo $\mathrm{j}=1 \mathrm{e}$ 2 ;

$\mathrm{E}_{(\mathrm{ij}) 1}=$ erro aleatório associado à parcela, suposto normal e independentemente distribuído, com média zero e variância $\sigma^{2}$;

$\mathrm{C}_{\mathrm{k}}=$ efeito da seção do trato gastrintestinal $\mathrm{k}$, sendo $\mathrm{k}=1,2,3$, 4 e 5 ;

$\mathrm{AC}_{\mathrm{ik}}=$ efeito da interação entre nível de concentrado i e seção do trato gastrintestinal k;

$\mathrm{BC}_{\mathrm{jk}}=$ efeito da interação entre grau de sangue $\mathrm{j}$ e seção do trato gastrintestinal $\mathrm{k}$;

$\mathrm{ABC}_{\mathrm{ijk}}=$ efeito da interação entre nível de concentrado $i$, grau de sangue $\mathrm{j}$ e seção do trato gastrintestinal k; e

$\mathrm{E}_{\mathrm{ijkl}}=$ erro aleatório associado à subparcela, suposto normal e independentemente distribuído, com média zero e variância $\sigma^{2}$.

Os dados foram interpretados por meio de análise de variância e regressão, adotando-se o nível de 5\% de probabilidade para o teste F. Os modelos foram escolhidos com base na significância dos coeficientes de regressão, por intermédio do teste de "Student" t, em nível de $5 \%$ de probabilidade, e do coeficiente de determinação. Para o processamento dos dados, utilizou-se o programa SAEG versão 7.0 (UFV, 1997).

\section{Resultados e Discussão}

\section{Bezerros Holandeses $x$ mestiços}

Não houve diferenças entre bezerros holandeses e mestiços para os parâmetros concentração de matéria seca (MS), fibra em detergente neutro (FDN), fibra em detergente ácido (FDA) e proteína bruta (PB).

QUEIROZ et al.(1996), trabalhando com animais de maior maturidade em diferentes grupos raciais, também não encontraram diferença nas concentrações de FDN. Características químicas da digesta no trato gastrintestinal

Teores de matéria seca - Os teores relativos de MS (\%) da digesta nas diferentes seções do trato gastrintestinal, dentro de cada ração experimental, diferiram $(\mathrm{P}<0,05)$ conforme resultados apresentados na Tabela 3.

$\mathrm{O}$ teor de matéria seca na digesta do rúmenretículo manteve-se constante $(\hat{\mathrm{Y}}=15,89)$ indepen-

Tabela 3 - Teor médio de matéria seca (\%) e regressão ajustada da digesta das seções do TGI, de bezerros de rebanhos leiteiros, submetidos a dietas com diferentes níveis de concentrado

Table 3 - Average dry matter content (\%) and fitted regression in the digesta of the GIT sections of dairy bull calves fed diets with different levels of concentrate

\begin{tabular}{|c|c|c|c|c|c|c|}
\hline \multirow{2}{*}{$\begin{array}{l}\text { Seção do TGI } \\
\text { GTI section }\end{array}$} & \multicolumn{4}{|c|}{ Tratamento (Treatment) } & \multirow{2}{*}{$\begin{array}{l}\text { Regressão } \\
\text { (Regression) }\end{array}$} & \multirow[t]{2}{*}{$\mathrm{R} 2$} \\
\hline & $\mathrm{C} 45$ & $\mathrm{C} 60$ & C75 & C90 & & \\
\hline $\begin{array}{l}\text { Retículo-rúmen } \\
\text { Reticulum-rumen }\end{array}$ & $16,0^{\mathrm{BC}}$ & $16,0^{\mathrm{B}}$ & $15,9^{\mathrm{B}}$ & $15,4^{\mathrm{B}}$ & $\hat{Y}=15,8925$ & - \\
\hline $\begin{array}{l}\text { Omaso } \\
\text { Omasum }\end{array}$ & $20,0^{\mathrm{A}}$ & $20,9^{\mathrm{A}}$ & $24,6^{\mathrm{A}}$ & $29,9^{\mathrm{A}}$ & $\hat{Y}=29,5255-0,4298 * X+0,0048 * X 2$ & 0,9989 \\
\hline $\begin{array}{l}\text { Abomaso } \\
\text { Abomasum }\end{array}$ & $18,0^{\mathrm{AB}}$ & $18,4^{\mathrm{AB}}$ & $21,3^{\mathrm{A}}$ & $28,8^{\mathrm{A}}$ & $\hat{\mathrm{Y}}=39,6940-0,8341 * \mathrm{X}+0,0079 * \mathrm{X} 2$ & 0,9969 \\
\hline $\begin{array}{l}\text { Intestino delgado } \\
\text { Small intestine }\end{array}$ & $9,5^{\mathrm{D}}$ & $8,9^{\mathrm{C}}$ & $8,7^{\mathrm{C}}$ & $8,7^{\mathrm{C}}$ & $\hat{Y}=9,0100$ & - \\
\hline $\begin{array}{l}\text { Intestino grosso } \\
\text { Large intestine }\end{array}$ & $13,2^{\mathrm{CD}}$ & $14,7^{\mathrm{B}}$ & $15,4^{\mathrm{B}}$ & $18,1^{\mathrm{B}}$ & $\hat{\mathrm{Y}}=8,5300+0,1020 * \mathrm{X}$ & 0,9384 \\
\hline
\end{tabular}

Médias, na coluna, seguidas de difere

$\hat{\mathrm{Y}}=$ teor médio ajustado de matéria seca $(\%)$

$\mathrm{X}=$ nível de concentrado na dieta.

* Significant by the $t$ test $[P<.05])$.

Means, within the column, followed by different letter are different $(P<.05)$ by Tukey test.

$\hat{\mathrm{Y}}=$ Fitted dry matter content (\%).

$\mathrm{X}=$ Concentrate level in the diet. 
dente dos diferentes níveis de concentrado estudados, não ocorrendo diferença entre os valores 15,45 a 16,09\% (Tabela 3). Estas observações concordam com as encontradas por VIDAL et al. (1969), EVANS et al. (1973), REYES (1975), WHAGHORN et al. (1986) e QUEIROZ et al. (1996), que registraram valores de 16,$30 ; 15,20 ; 16,13 ; 15,00$; e 15,77 , respectivamente, em diferentes situações de alimentação.

$\mathrm{O}$ teor de MS do conteúdo ruminal varia de acordo com o consumo, segundo vários autores citados por OWENS e GOETSCH (1986). No entanto, RIBEIRO (1996), trabalhando com estes mesmos bezerros e mesmas dietas, não encontrou efeito dos níveis de concentrado sobre o consumo de MS.

$\mathrm{O}$ teor de MS mais alto foi encontrado no omaso e abomaso, uma vez que, no omaso, verifica-se a adaptação deste órgão em absorver grande quantidade de líquidos da digesta do rúmen-retículo. Os resultados, exceto do abomaso, são semelhantes àqueles encontrados por BOYNE et al. (1956), YANG e THOMAS (1965), VIDAL et al. (1969), WHAGORN et al. (1986) e QUEIROZ et al. (1996). Foi observado efeito quadrático $(\mathrm{P}<0,05)$ dos níveis de concentrado sobre o teor de MS no omaso, sendo o teor mínimo obtido para o nível de $44,77 \%$ de concentrado (Tabela 3), provavelmente devido à maior densidade das rações concentradas, que é uma característica do alimento.

No abomaso, também encontrou-se efeito quadrático $(\mathrm{P}<0,05)$ dos níveis de concentrado sobre o teor de MS (Tabela 3). Os valores foram superiores aos encontrados por HOOGAN e PHILLIPSON (1960), VIDAL et al. (1969), REYES (1975) e QUEIROZ et al. (1996). No entanto, após o abate e remoção do TGI, foi encontrada pouca digesta no abomaso dos animais, visto que em alguns a quantidade foi suficiente para uma amostragem muito pequena. Isto pode ser atribuído ao esvaziamento gástrico que ocorreu durante o período de jejum, restando apenas a fração mais sólida da digesta e, portanto, com maior teor de MS. A condição normal in vivo são digestas abomasais com baixo teor de MS, devido à adição de água e às secreções de suco gástrico (YANG e THOMAS, 1965).

O menor teor de $\mathrm{MS}(\hat{\mathrm{Y}}=9,01)$ foi encontrado no intestino delgado; este se manteve constante nos diferentes níveis de concentrado estudado, não ocorrendo diferença entre os valores de 8,77 a 9,58\% (Tabela 3). Estes valores são semelhantes aos encontrados por BADAWY et al. (1958), VIDAL et al. (1969), REYES (1975) e QUEIROZ et al. (1995), que justificaram estes baixos teores de MS pela incorporação de água no abomaso e pelas secreções endógenas de suco gástrico, bile e suco pancreático. No intestino grosso encontrou-se efeito linear positivo $(\mathrm{P}<0,05)$ dos níveis de concentrado sobre o teor de MS da digesta. Os resultados são semelhantes aos

Tabela 4 - Teor médio de fibra em detergente neutro (\%) e regressão ajustada na digesta das seções do TGI, de bezerros de rebanhos leiteiros, submetidos a dietas com diferentes níveis de concentrado

Table 4 - Neutral detergent fiber content (\%) and fitted regression in the digesta of GTI sections of dairy calves bull fed diets with different levels of concentrate

\begin{tabular}{lcccccc}
\hline $\begin{array}{l}\text { Seção do TGI } \\
\text { GTI section }\end{array}$ & \multicolumn{3}{c}{ Tratamento (Treatment) } & & $\begin{array}{c}\text { Regressão } \\
\text { Regression }\end{array}$ \\
\cline { 2 - 5 } $\begin{array}{l}\text { Retículo-rúmen } \\
\text { Reticulum-rumen }\end{array}$ & $77,2^{\mathrm{A}}$ & $76,2^{\mathrm{A}}$ & $75,5^{\mathrm{A}}$ & $75,3^{\mathrm{A}}$ & $\hat{\mathrm{Y}}=76,0925$ & $\mathrm{R}^{2}$ \\
$\begin{array}{l}\text { Omaso } \\
\begin{array}{l}\text { Omasum } \\
\text { Abomaso }\end{array}\end{array}$ & $70,0^{\mathrm{B}}$ & $64,3^{\mathrm{B}}$ & $58,5^{\mathrm{B}}$ & $51,6^{\mathrm{B}}$ & $\hat{\mathrm{Y}}=88,4720-0,4047^{*} \mathrm{X}$ & 0,9977 \\
$\begin{array}{l}\text { Abomasum } \\
\begin{array}{l}\text { Intestino delgado } \\
\text { Small intestine }\end{array}\end{array}$ & $51,1^{\mathrm{D}}$ & $47,1^{\mathrm{D}}$ & $42,4^{\mathrm{D}}$ & $38,8^{\mathrm{C}}$ & $\hat{\mathrm{Y}}=63,6060-0,2772 * \mathrm{X}$ & 0,9980 \\
$\begin{array}{l}\text { Intestino grosso } \\
\text { Large intestine }\end{array}$ & $58,9^{\mathrm{C}}$ & $24,6^{\mathrm{E}}$ & $18,8^{\mathrm{E}}$ & $17,3^{\mathrm{D}}$ & $\hat{\mathrm{Y}}=39,2130-0,2516^{*} \mathrm{X}$ & 0,9574 \\
\hline
\end{tabular}

Médias, na coluna, seguidas de diferentes letras são diferentes $(P<0,05)$ pelo teste Tukey.

* Significativo $(P<0,05)$, pelo teste "t".

$\hat{Y}=$ teor médio ajustado de matéria seca $(\%)$.

$\mathrm{X}=$ nível de concentrado na dieta.

* Significant by the $t$ test $[P<.05])$.

Means, within the column, followed by different letter are different $(P<.05)$ by Tukey test.

$\hat{\mathrm{Y}}=$ Fitted dry matter content $(\%)$.

$\mathrm{X}=$ Concentrate level in the diet. 
Tabela 5 - Teor médio de fibra em detergente ácido (\%) e regressão ajustada na digesta das seções do TGI, de bezerros de rebanhos leiteiros, submetidos a dietas com diferentes níveis de concentrado

Table 5 - $\quad$ Acid detergent fiber content (\%) and fitted regression in the digesta of the GTI sections of dairy bull calves fed diets with different levels of concentrate

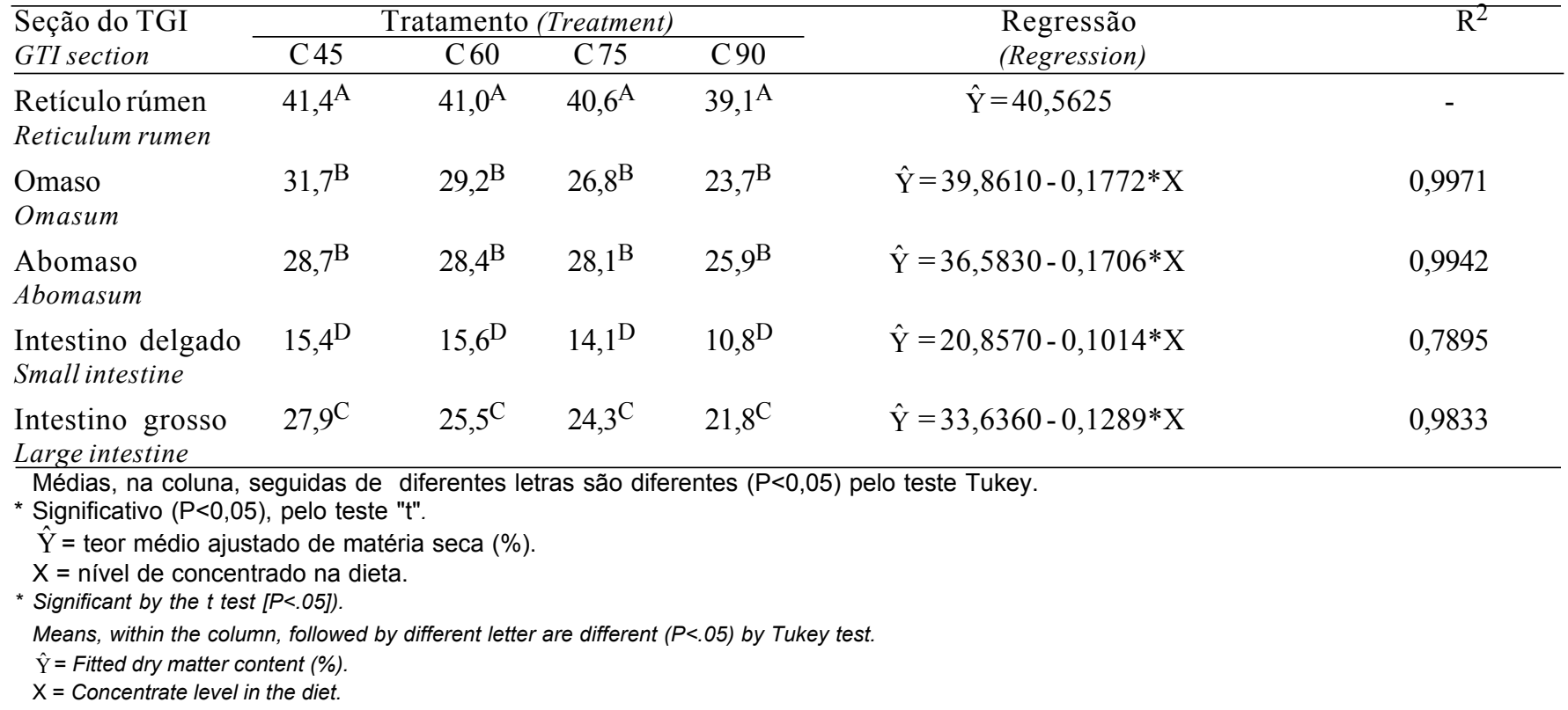

encontrados por REYES (1975) e QUEIROZ et al. (1996), para os tratamentos cujos níveis de concentrado na dieta foram de 45 e $60 \%$. Em comparação à digesta do intestino delgado, observou-se no intestino grosso aumento no teor de MS, possivelmente devido à absorção de água neste local. Estes resultados concordam com GROVUM e HECKER (1973) e HOOVER (1978), que também reportaram declínio no teor de água da digesta do intestino grosso, e KAY e PFEFFER (1970), ao quais constataram que $90 \%$ da água que passa pelo intestino grosso são absorvidos neste local.

Teores de fibra em detergente neutro e em detergente ácido - Os teores de FDN ( $\hat{\mathrm{Y}}=76,09)$ e FDA ( $\hat{Y}=40,56)$ no rúmen-retículo (Tabelas 4 e 5) mantiveram-se constantes na digesta dos bezerros, independente dos níveis de concentrado. Isto ocorreu provavelmente em virtude de grande aumento na taxa de passagem do concentrado em relação à taxa de passagem do volumoso, associado ao longo tempo de jejum, havendo um processo de concentração da fibra, segundo Belyea et al.(1979), Coombe et al. (1979) e Wheeler et al. (1979), citados por OWENS e GOETSCH (1986). Eng et al. (1964), citados por OWENS e GOETSCH (1986), verificaram que a taxa de passagem do feno foi independente da taxa de passagem do concentrado, em ovelhas alimentadas com diferentes níveis de concentrado. Neste trabalho, este processo pode ter sido acentuado devi- do à baixa qualidade do feno utilizado, pois apresentava alto teor de FDN. De acordo com Akin e Barton (1983), citados por OWENS e GOETSCH (1986), o caule dos volumosos possui grande proporção de tecido lignificado que resiste à degradação microbiana.

Nas demais seções do TGI, omaso, abomaso, intestino delgado e intestino grosso, houve efeito linear negativo $(\mathrm{P}<0,05)$ dos níveis crescentes de concentrado sobre os teores de FDN e FDA (Tabelas 5 e 6). Esta diminuição se explica, em parte, pela redução dos teores de FDN e FDA nas rações experimentais. Nos níveis mais elevados de concentrado, poderia ter havido subutilização da fibra, pois, quando os microrganismos dispõem de material facilmente fermentável, ocorre diminuição do processo de fermentação da fibra (MITCHELL JR. et al., 1967).

Os menores teores de FDN e FDA foram encontrados no intestino delgado (Tabelas 4 e 5), provavelmente, devido ao processo de diluição (REYES, 1975).

A interpretação dos resultados dos teores de FDN e FDA pode ser feita considerando que são influenciados pelos processos de digestão, absorção e secreção ao longo do TGI, conforme BOYNE et al. (1956), COELHO DA SILVA et al. (1972), PERÓN e RUÍZ (1972) e TERNOUTH e BUTTLE (1973), o que implica em processos de diluição e concentração da digesta, influenciando o teor final dos nutrientes em estudo.

Nos diferentes níveis de concentrado, houve diminui- 
Rev. bras. zootec.

Tabela 6 - Teor médio de proteína bruta (\%) e regressão ajustada na digesta das seções do TGI, de bezerros de rebanhos leiteiros, submetidos a dietas com diferentes níveis de concentrado

Table 6 - Crude protein content (\%) and fitted regression in the digesta of GTI sections of dairy bull calves fed diets with differents levels of concentrate

\begin{tabular}{|c|c|c|c|c|c|c|}
\hline \multirow{2}{*}{$\begin{array}{l}\text { Seção do TGI } \\
\text { GTI section } \\
\end{array}$} & \multicolumn{4}{|c|}{ Tratamento (Treatment) } & \multirow{2}{*}{$\begin{array}{l}\text { Regressão } \\
\text { (Regression) }\end{array}$} & \multirow[t]{2}{*}{$\mathrm{R} 2$} \\
\hline & $\mathrm{C} 45$ & $\mathrm{C} 60$ & $\mathrm{C} 75$ & $\mathrm{C} 90$ & & \\
\hline $\begin{array}{l}\text { Retículo-rúmen } \\
\text { Reticulum-rumen }\end{array}$ & $11,47^{\mathrm{B}}$ & $10,49^{\mathrm{C}}$ & $9,52^{\mathrm{C}}$ & $10,41^{\mathrm{D}}$ & $\hat{\mathrm{Y}}=10,4725$ & - \\
\hline $\begin{array}{l}\text { Omaso } \\
\text { Omasum }\end{array}$ & $14,61^{\mathrm{B}}$ & $16,93^{\mathrm{B}}$ & $18,50^{\mathrm{B}}$ & $21,36^{\mathrm{B}}$ & $\hat{\mathrm{Y}}=8,0310+0,1455^{*} \mathrm{X}$ & 0,9883 \\
\hline $\begin{array}{l}\text { Abomaso } \\
\text { Abomasum }\end{array}$ & $12,59^{\mathrm{B}}$ & $13,42^{\mathrm{BC}}$ & $14,15^{\mathrm{B}}$ & $15.45^{\mathrm{C}}$ & $\hat{\mathrm{Y}}=9,7130+0,0621 * \mathrm{X}$ & 0,9824 \\
\hline $\begin{array}{l}\text { Intestino delgado } \\
\text { Small intestine }\end{array}$ & $30,28^{\mathrm{A}}$ & $31,12^{\mathrm{A}}$ & $36,84^{\mathrm{A}}$ & $37,26^{\mathrm{A}}$ & $\hat{\mathrm{Y}}=21,8780+0,1777^{*} \mathrm{X}$ & 0,8718 \\
\hline $\begin{array}{l}\text { Intestino grosso } \\
\text { Large intestine }\end{array}$ & $13,67^{\mathrm{B}}$ & $15,62^{\mathrm{B}}$ & $15,86^{\mathrm{B}}$ & $16,27^{\mathrm{C}}$ & $\hat{\mathrm{Y}}=15,3550$ & - \\
\hline $\begin{array}{l}\text { Médias, na coluna, } \\
\text { * Significativo }(P<0,0 \\
\hat{Y}=\text { teor médio ajus } \\
X=\text { nível de concen } \\
\text { * Significant by the } t \text { tes }\end{array}$ & $\begin{array}{l}\text { eguidas c } \\
\text {, pelo tes } \\
\text { ado de } \mathrm{m} \\
\text { ado na d } \\
[P<.05]) \text {. }\end{array}$ & $\begin{array}{l}\text { ferentes le } \\
\text { a seca }(\%)\end{array}$ & as são d & ntes $(P<$ & lo teste Tukey. & \\
\hline $\begin{array}{l}\text { Means, within the colu } \\
\hat{\mathrm{Y}}=\text { Fitted dry matter } \\
\mathrm{X}=\text { Concentrate level }\end{array}$ & $\begin{array}{l}\text {, followed } \\
\text { ent (\%). } \\
\text { he diet. }\end{array}$ & erent let & & 5) by & & \\
\hline
\end{tabular}

ção do teor de FDN e FDA $(\mathrm{P}<0,05)$ da digesta omasal, em relação à digesta ruminal (Tabelas 4 e 5), concordando com observações feitas por QUEIROZ et al. (1996).

Os teores de FDN e FDA na digesta do intestino grosso diminuíram $(\mathrm{P}<0,05)$ em relação à digesta omasal, em todos os níveis de concentrado estudados. Resultados de experimentos feitos com animais canulados no duodeno e íleo mostraram que grande parte da celulose e hemicelulose digerida no intestino grosso ocorre, possivelmente, no ceco e cólon. Existem algumas exceções em que 9 a $14 \%$ da celulose foram digeridos no intestino delgado, o que possivelmente é atribuído à contaminação de bactérias do intestino grosso na região íleo-cecal. Até 30\% da digestão da celulose e hemicelulose podem ocorrer no intestino grosso. Os maiores valores estavam associados à inclusão de cereal na dieta ou à moagem e peletização (COELHO DA SILVA e LEÃO, 1979).

Teores de proteina bruta - Os menores teores de PB foram encontrados na digesta ruminal, porém não apresentaram diferenças entre algumas seções do TGI (Tabela 6), estando próximos dos encontrados por QUEIROZ et al. (1996), que reportaram teores entre 10,56 e $12,69 \%$. O teor de PB na digesta do rúmen-retículo $(\hat{\mathrm{Y}}=10,47)$ manteve-se constante nos diferentes níveis de concentrado estudado, não ocorrendo diferença entre os valores 9,52 a 11,47\%. Segundo o NRC (1985), a extensão da degradação da proteína no rúmen-retículo depende, sobretudo, da atividade proteolítica microbiana naquele local, do acesso microbiano à proteína e da renovação do conteúdo ruminal. Em várias condições de alimentação, foi reportada pequena diferença no potencial proteolítico da digesta do rúmen-retículo, concluindo-se que o acesso microbiano à proteína seria o fator mais importante a influenciar a degradação protéica e o fator principal a influir na concentração deste nutriente.

$\mathrm{Na}$ digesta omasal houve efeito linear crescente $(\mathrm{P}<0,05)$ dos níveis de concentrado na dieta sobre os teores de PB. A hipótese para explicar esta observação é o aumento da fermentação microbiana favorecido pela maior disponibilidade de matéria orgânica digestível. Gosshtasbpour-Parsi et al. (1979), citados por SMITH (1984), observaram aumento no teor de composto nitrogenado, na digesta omasal, causado pela fermentação microbiana. Houve aumento linear $(\mathrm{P}<0,05)$ nos teores de $\mathrm{PB}$, em função dos níveis de concentrado na digesta abomasal, mas não diferiram dos valores encontrados no omaso, exceto para o nível de $90 \%$ de concentrado (Tabela 6).

Os maiores teores de PB foram obtidos no intestino delgado, sendo os valores próximos aos encontrados por QUEIROZ et al. (1996), que relataram teores variando entre 31,94 e 35,44\% para os animais alimentados à vontade. REYES (1975) também verificou grande aumento deste nutriente no intestino 
delgado em relação às demais seções.

Houve efeito linear crescente $(\mathrm{P}<0,05)$ dos níveis de concentrado na dieta sobre o teor de $\mathrm{PB}$ na digesta do intestino delgado.

Nicholson e Sutton (1969), citados por COELHO DA SILVA e LEÃO (1979), mostraram que houve ganho líquido de compostos nitrogenados, quando compararam a quantidade ingerida com a presente no duodeno. Isto ocorreu em carneiros alimentados com dieta que continha grande proporção de grãos, suprindo três vezes sua exigência energética de mantença. Por sua vez, Annison et al. (1954), citados por COELHO DA SILVA e LEÃO (1979), ao verificarem que grãos de cereais são mais resistentes alimentos à fermentação no rúmen, admitiram que isto foi favorável ao aumento da passagem de proteína dietética do rúmen para as partes inferiores do TGI de carneiros que receberam dietas ricas em grãos que continham proteína de alta qualidade.

Os compostos nitrogenados que chegam ao ceco são proveniente do íleo e da difusão através da parede intestinal (NRC, 1985), podendo ser utilizados na síntese de proteína microbiana, que aumenta com o nível de açúcar ou amido (Orskov et al., 1975, citados por HOOVER, 1978). Embora não houvesse efeito dos níveis crescentes de concentrado, observou-se aumento de 2,6\% na concentração de PB.

Segundo ULYATT et al. (1976), alguns aminoácidos podem ser absorvidos no intestino grosso, mas, nutricionalmente, a quantidade tem sido insignificante, tornando-se questionável o valor da proteína microbiana sintetizada neste local. Portanto, de acordo com HOOVER (1978), a principal contribuição do intestino grosso dos ruminantes no metabolismo do nitrogênio é na recuperação e transferência deste para os fluídos corporais, em que poderia ser usado na síntese de aminoácidos não-essenciais ou retornar ao rúmen para a síntese de proteína microbiana.

\section{Conclusões}

Os teores de MS no rúmen-retículo e no intestino delgado permaneceram constantes; não obstante, no intestino grosso ocorreu efeito linear crescente e, no omaso e abomaso, efeito quadrático crescente, em função dos níveis de concentrado na dieta. Entre todas as seções do TGI, os menores valores de MS foram encontrados no intestino delgado e os maiores, no omaso e abomaso.

Os teores de FDN e FDA mantiveram-se constantes no rúmen-retículo, mas, nas demais seções do
TGI, houve efeito linear decrescente, em função do níveis de concentrado na dieta. Ao longo do TGI, os menores teores de FDN e FDA foram encontrados no intestino delgado e os maiores, no rúmen-retículo.

Os teores de PB mantiveram-se constantes no rúmen-retículo e no intestino grosso; todavia, no omaso, abomaso e intestino delgado, houve efeito linear crescente, com o aumento dos níveis de concentrado na dieta. Ao longo do TGI, os maiores teores de PB foram encontrados no intestino delgado.

\section{Referências Bibliográficas}

BADAWY, A.M., CAMPBELL, R.M. 1958. Further studies on the changing composition of the digesta along the alimentary tract of the sheep. Changes in the omasum, Br. J. Nut., 12(10):384-391.

BOYNE, A.W., CAMPBELL, R.M., DAVIDSON, J. et al. 1956. Changes in composition of the digesta along the alimentary tract of sheep. Br. J. Nut., 10(5):325-332.

COELHO DA SILVA, J.F., LEÃO, M.I. 1979. Fundamentos de nutrição dos ruminantes. Piracicaba: Livroceres, p.71.

COELHO DA SILVA, J.F., SEELEY, R.C., THOMSON, D.J. et al. 1972. The effect in sheep of physical form on the sites of digestion of a dried lucerne diet. 2. sites of nitrogen digestion. Br. J. Nut., 28(43):1432-1442.

CZERKAWSKY, J.M. 1986. A simple model to describe the flow of large and small particles in the rumen. In: Nuclear and related technique in animal production and health, Proc. Symposium of International Atomic Energy Agency, Viena.

EVANS, E.W., PEARCE, G.R., BURNETT, J. 1973. Changes in some physical characteristic of the digesta in the reticulorumen of cows fed once daily. Br. J. Nut., 29(1):357-376.

FORBES, J.M., FRANCE, J. 1993. Special features of the ruminant. In: FORBES, J.M, FRANCE, J. (Eds.) Quantitative aspects of ruminant digestion and metabolism, Cambridge: CAB Int., p.107-122.

GROVUM,W.L, HECKER, J.F. 1973. The effect of level of food intake on digesta retention times and on water and electrolyte absorption in the large intestine. Br. J. Nut., 30(2):221-229.

HOOGAN, J.P., PHILLIPSON, A.T. 1960. The rate of transport of food along the digestive tract of sheep. Br. J. Nut., 14(1):147-155.

HOOVER, W. H. 1978. Digestion and absorption in the hindgut of ruminants. J. Anim. Sci., 46(6):1789-1797.

KAY, R. N. B, PFEFFER, E. 1970. Movements of water and electrolytes into and from the intestines of the sheep. In: PHILliPSON, A.T. (Ed). Physiology of digestion and metabolism in the ruminant. England: Oriel Press, 1970. p.242-241.

MITCHELL JR., G.E., LITTLE, C.O., KARR, M.R. et al. 1967. Pre-abomasal and post-abomasal cellulose digestion in steers. Kentucky Anim. Sci. Research Reports, 1(20):243-252.

NATIONAL RESEARCH COUNCIL - NRC. 1985. Ruminant nitrogen usage. Washington, D.C., 138p.

NATIONAL RESEARCH COUNCIL - NRC. 1988. Nutrient requirements of dairy cattle. Washington, D.C. $157 \mathrm{p}$.

OSBOURN, D.F., BEEVER, D.E., THOMSON, D.J. 1976. Influence of physical processing on the intake, digestion and utilization of dried herbage. Proc. Nutr. Soc., 35(1):191-203.

OWENS, F.N., GOETSCH, A.L. 1986. Digesta passage and 
microbial protein synthesis. In: MILLINGAN, L. P., GROVUM, W.L., DOBSON, A. (Eds). Control of digestion and metabolism in ruminants. New Jersey: Englewood Cliffs, Prentice Hall, p.196-223.

PERÓN, N., RUÍZ, R., 1972. Desarrollo anatómico del tracto gastrointestinal en terneros alimentados con dietas basadas en miel o concentrados. R. Cub. C. Agric., 6(2):351-358.

POPPI, D.P., NORTON, B.W., MINSON, D.J. et al. 1980. The validity of the critical size theory for particles leaving the rumen. J. Agric. Sci., 94(2):275-280.

QUEIROZ, A.C., REYES SANCHEZ, N., PEREIRA, J.C. et al., 1996. Concentração de nutrientes ao longo do trato gastrintestinal de ruminantes de diferentes grupos genéticos. R. Soc. Bras. Zootec., 25(2):309-323.

REYES, Y. 1975. Composicion de la digesta en el tracto gastrointestinal de bovinos com dietas de forrage y alto contenido de miel. 1. Utilizacion del forrage. R. Cub. C. Agric., 9(3): 347-356.

RIBEIRO, T. R. Desempenho e qualidade da carcaça de bezerros holandeses, alimentados com dietas contendo diferentes niveis de concentrado. Viçosa: UFV, 1996.89 p. Dissertação(Mestrado em Zootecnia) - Universidade Federal de Viçosa, 1996.

SILVA, D.J. 1990. Análise de alimentos (Métodos químicos e biológicos). Viçosa: UFV, Impr. Univ. $165 \mathrm{p}$.

SMITH, R.H. 1984. Microbial activity in the omasum. Proc. Nutr. Soc., 43(1):63-68.

TERNOUTH, J.H., BUTTLE, H.L. 1973. Concurrent studies on the flow of digesta in the duodenum and of exocrine pancreatic secretion of calves. Br. J. Nut., 29(2):387-396.

ULYATT, M.J., BALDWIN, R.L., KOOMG, L.J. 1976. The basic nutritive value. A modelling approach. Proc. N. Z. Soc. Anim. Prod., 36(1):140-149.
UNIVERSIDADE FEDERAL DE VIÇOSA (UFV). S.A.E.G. (Sistema de Análises Estatísticas ). Viçosa, MG, 1997 (Versão 7.0).

UMPHREY, J.E., STAPLES, C.R. 1994. General anatomy of the ruminant digestive system. In: WEBB, D.W. (Ed.) Dairy science handbook. Gainesville: Univ. of Florida. p. 14-16.

VAN SOEST, P. J. 1994. Nutritional ecology of the ruminant.2. ed. Ithaca: Cornell University Press, 476p.

VAN SOEST, P.J., ROBERTSON, J.B., LEWIS, B.A. 1991. Methods for dietary fiber, neutral detergent fiber, and nonstarch polysaccharides in relation to animal nutrition. $J$. Dairy Sci., 74(10):3583-3597.

VIDAL, H.M., HOGUE, D.E., ELLIOTT, J.M. et al. 1969. Digesta of sheep fed different hay-grain ratios. J. Anim. Sci., 29(1):62-68.

WAGHORN, G.C., REID, C.S.W., ULYATT, M.J. et al. 1986. Feed comminution, particle composition and distribution between a the four compartments of the stomach in sheep fed chopped lucerne hay at two feeding frequencies and intake level. J. Agric. Sci., 106(1):287-296.

YANG, M.G., THOMAS, J.W. 1965. Absortion and secretion of some organic and inorganic constituents and the distribution of these constituents throughout the alimentary tract of young calves. Br. J. Nut., 87(3):444-456.

Recebido em: 27/05/98

Aceito em: 08/01/99 